\title{
Acidic Monetite Complex Paste with Bleaching Property for In-depth Occlusion of Dentinal Tubules
}

This article was published in the following Dove Press journal: International Journal of Nanomedicine

\author{
Bolin Li $\mathbb{D}^{\prime}$ \\ Chunyan Liu ${ }^{2,3}$ \\ Ze-hui Fang 4 \\ Ying Cao ${ }^{4}$ \\ Zheng Zhou ${ }^{3}$ \\ Haiyan $\mathrm{Lu}^{2}$ \\ 'Hebei Key Laboratory of Stomatology, \\ Hebei Clinical Research Center for Oral \\ Diseases, School \& Hospital of \\ Stomatology, Hebei Medical University, \\ Shijiazhuang 0500 I7, People's Republic of \\ China; ${ }^{2}$ Department of Orthodontics, \\ Hebei Key Laboratory of Stomatology, \\ Hebei Clinical Research Center for Oral \\ Diseases, School \& Hospital of \\ Stomatology, Hebei Medical University, \\ Shijiazhuang 0500 I7, People's Republic of \\ China; ${ }^{3}$ School of Dentistry, University of \\ Detroit Mercy, Detroit, Michigan 48208, \\ USA; ${ }^{4}$ School \& Hospital of Stomatology, \\ Anhui Medical University, Hefei 230032, \\ People's Republic of China
}

Correspondence: Zheng Zhou School of Dentistry, University of Detroit Mercy, 2700 Martin Luther King Jr. Blvd,

Detroit, Michigan 48208, USA

Tel + I-3 I 3-494-6667

Fax + I-313-494-6666

Email zhouzh I@udmercy.edu

Haiyan Lu

Department of Orthodontics, Hebei Key Laboratory of Stomatology, Hebei Clinical

Research Center for Oral Diseases, School

\& Hospital of Stomatology, Hebei Medical

University, 383 Zhongshan East Road,

Shijiazhuang, Hebei 0500 I7, People's

Republic of China

$\mathrm{Tel} / \mathrm{Fax}+86$ 3I I-86265748

Email luhaiyan67@I63.com
Background: Dentin hypersensitivity (DH) is a common dental clinical condition presented with a short and sharp pain in response to physical and chemical stimuli. Currently no treatment regimen demonstrates long-lasting efficacy in treating $\mathrm{DH}$, and unesthetic yellow tooth color is a concern to many patients with DH.

Aim: To develop a bi-functional material which can occlude dentinal tubules in-depth and remineralize dentin for long-lasting protection of the dentin-pulp complex from stimuli and bleach the tooth at the same time.

Methods: A mixture containing $\mathrm{CaO}, \mathrm{H}_{3} \mathrm{PO}_{4}$, polyethylene glycol and $\mathrm{H}_{2} \mathrm{O}_{2}$ at a specific ratio was mechanically ground using a planetary ball. The mineralizing complex paste was characterized by X-ray diffraction (XRD) and scanning electron microscopy (SEM). Dentin was exposed to the synthesized paste for $8 \mathrm{~h}$ and $24 \mathrm{~h}$ in vitro. The mineralizing property was evaluated using SEM and microhardness tests. Red tea-stained tooth slices were exposed to the synthesized paste for $8 \mathrm{~h}$ and $24 \mathrm{~h}$ in vitro. The bleaching effect was characterized by a spectrophotometer.

Results: The complex paste had very a fine texture, was injectable, and had a gel-like property with 2.6 (mass/volume) $\% \mathrm{H}_{2} \mathrm{O}_{2}$ concentration. The X-ray diffraction pattern showed that the inorganic phase was mainly monetite $\left(\mathrm{CaHPO}_{4}\right)$. The mineralizing complex paste induced the growth of inorganic crystals on the dentin surface and in-depth occlusion of dentin tubules by up to $80 \mu \mathrm{m}$. The regenerated crystals were integrated into the dentin tissue on the dentin surface and the wall of dentinal tubules with a microhardness of up to $126 \mathrm{MPa}$ (versus $137 \mathrm{Mpa}$ for dentin). The paste also bleached the stained dental slices.

Conclusion: The mineralizing complex paste is a promising innovative material for efficient DH management by remineralizing dentin and in-depth occlusion of dentin tubules, as well as tooth bleaching.

Keywords: dentin hypersensitivity, remineralization, tooth whitening, planetary ball mill

\section{Introduction}

Dentin hypersensitivity (DH) is a common dental clinical condition characterized by a short, sharp pain in response to thermal, evaporative, tactile, osmotic, or chemical stimuli. It is caused by the exposure of dentinal tubules after gingival recession or enamel loss due to erosion or abrasion. ${ }^{1,2}$ The prevalence of $\mathrm{DH}$ ranges from $3-98 \%$ in general, and $40-60 \%$ of adults aged $18-65$ years suffer from $\mathrm{DH}$ with potential impairment of their oral-health-related quality of life. ${ }^{3-6}$ Brännström's hydrodynamic theory is widely accepted as the explanation for the 
mechanism of DH pain. It refers to the rapid movement of the fluid in dentinal tubules that occurs under an array of stimuli; such movement can either damage odontoblasts or activate the nerve terminals to cause pain. ${ }^{7,8}$ Based on this theory, the main strategy to treat $\mathrm{DH}$ is to reduce dentin permeability by blocking/occluding dentinal tubules. ${ }^{9-11}$ Current materials for dentinal tubule occlusion include sodium fluoride/stannous fluoride, ${ }^{12-14}$ strontium chloride/acetate, ${ }^{15,16}$ potassium oxalate, ${ }^{17-19}$ arginine, ${ }^{20,21}$ calcium phosphate and its composites, ${ }^{22-31}$ bioglass and silicates, ${ }^{32-43}$ laser, ${ }^{44,45}$ gallic acid (tannin) $/ \mathrm{Fe}^{3+}$ complex, ${ }^{47,48}$ amyloid-like aggregation coating, ${ }^{49}$ and selfassembly peptide. ${ }^{51}$ Although some of these demonstrate clinical effectiveness in tooth desensitization, no treatment regimen presently exhibits long-lasting efficiency in treating $\mathrm{DH}^{46,52-61}$ The desensitizing duration is limited because the penetration depth of the precipitation into dentinal tubules is less than $10 \mu \mathrm{m} ;{ }^{43,49}$ consequently, the tubules cannot withstand the stresses of the oral environment, such as erosion, brushing and chewing force, tooth wear, and degradation over time. Therefore, efficient and enduring materials must be developed for in-depth dentinal tubule occlusion. Recently, a mineralizing method to occlude deep dentinal tubules (up to $60 \pm 5 \mu \mathrm{m}$ ) was developed by using amyloid-like protein to coat dentin. ${ }^{50}$

In natural tooth, enamel plays the most important and effective role in protecting the underlying dentine-pulp tissue from external stimuli. Biomimetic mineralization can create an enamel-like layer on the exposed dentin that resembles natural enamel to protect the dentine-pulp tissue underneath from external stimuli. ${ }^{53}$ Therefore, a biomimetic mineralizing strategy for occluding the dentinal tube in-depth and growing an enamel-like layer on the exposed dentin to protect the dentin-pulp complex may be ideal way for treating DH and providing long-lasting relief from DH pain.

Exposed dentin is often yellow or brown, which is an esthetic concern for many DH patients. leading them to pursue tooth whitening (tooth bleaching). ${ }^{62,63}$ The application of hydrogen peroxide (HP) is an established approach for tooth whitening. The "chromophore theory" is widely accepted as the tooth bleaching mechanism by which peroxide exerts its whitening effects. ${ }^{64}$ The bleaching agents release reactive free radicals, reactive oxygen species and HP ions that will degrade chromophores. However, the reactive oxygen species will diffuse through dentin and reach the pulp chamber to cause DH. DH is often a side effect of tooth bleaching. Approximately $80 \%$ of patients who have had their teeth bleached experience DH, according to a report that includes input from more than 7000 dentists. ${ }^{64}$

In this study, we propose using a mineralizing system with HP to manage DH and stained teeth at the same time. The mineralizing system deeply occludes dentin tubules and provides a layer of minerals on an exposed dentin surface, and HP bleaches the tooth. Though HP may increase DH temporarily during the treatment process, the deeply occluded dentin tubules and the mineral layer on exposed dentin surface may prevent dentinal sensitivity after the treatment. For this purpose, a novel calcium phosphate mineralizing system with bleaching agents was developed using a mechanochemical method, and its mineralizing and bleaching effects were evaluated in vitro.

\section{Materials and Methods Synthesis and Characterization of the Mineralizing Complex Synthesis}

A mixture containing $16.8 \mathrm{~g}$ of $\mathrm{CaO}, 13.68 \mathrm{~mL}$ of $85 \% \mathrm{H}_{3}$ $\mathrm{PO}_{4}, 24 \mathrm{~mL}$ of distilled water $(\mathrm{Ca} / \mathrm{P}$ molar ratio $=1.67)$, and $7.5 \mathrm{~g}$ of polyethylene glycol (PEG, average molecular weight of 20,000) was prepared, and its $\mathrm{pH}$ value was adjusted to about 8.0 with $1 \mathrm{M} \mathrm{NaOH}$ solution. Then, the mixture was mechanically ground using a planetary ball mill (YXQM-2L, MITR, Changsha, China) with a $50 \mathrm{~mL}$ zirconia jar and zirconia balls at ambient temperature and at a rotation speed of $250 \mathrm{rpm}$ for $8 \mathrm{~h}$. Then, the $\mathrm{pH}$ value of the paste was adjusted to about 3 by using $9 \mathrm{~mL}$ of $85 \%$ $\mathrm{H}_{3} \mathrm{PO}_{4}$. Thereafter, the mixture was ground again for $1 \mathrm{~h}$, and its $\mathrm{pH}$ stability was verified. The mixture was dried in an oven at $60{ }^{\circ} \mathrm{C}$ for $24 \mathrm{~h}$. After drying, $24 \mathrm{~mL}$ of $6 \% \mathrm{HP}$ was added, and the mixture was ground again for $1 \mathrm{~h}$ to obtain a calcium phosphate complex paste containing HP.

For the control group, the paste only contained PEG, distilled water and HP and was prepared using the same method with the same concentration, and its $\mathrm{pH}$ value was also adjusted to 3 with $\mathrm{H}_{3} \mathrm{PO}_{4}$.

$\mathrm{CaO}$ and $\mathrm{H}_{3} \mathrm{PO}_{4}$ were purchased from Sigma-Aldrich (St. Louis, MO, USA). HP and PEG were purchased from Solarbio (Beijing, China).

\section{Characterization}

\section{X-Ray Powder Diffraction}

The complex paste was dried, and X-ray powder diffraction (XRD) (PHILIPS X'Pert PRO) was conducted to determine the structure of the inorganic component. 


\section{Field Emission Scanning Electron Microscopy}

After the complex paste was dried and sputter-coated with gold, the morphological features were examined via field emission scanning electron microscopy (FESEM) (Sirion 200, FEI).

\section{Hydrogen Peroxide Concentration}

One milliliter of the paste was extracted and centrifuged at $10,000 \mathrm{rpm}$ for $10 \mathrm{~min}$. The supernatant was obtained and diluted to $1 \mathrm{~mL}$ with distilled water for the determination of HP concentration. HP concentration was measured using an HP test kit (Solarbio, Beijing, China) and a UVvisible spectrophotometer (UV-1800, Shimadzu, Japan) at $415 \mathrm{~nm}$ in accordance with the manufacturer's instructions.

\section{Tooth Slice Mineralization Protocol and Characterization}

All methods were implemented in accordance with the relevant guidelines and regulations of the Independent Ethics Committee of the Hospital of Stomatology, Hebei Medical University (No. 2019 030). The written informed consents were obtained from all subjects/participants or their legal guardians to have the case details and any accompanying images published.

\section{Tooth Slice Preparation}

Human third molars were collected with consent from patients requiring extraction. The teeth were stored at $4^{\circ}$ $\mathrm{C}$ in a solution ( $\mathrm{pH} 7.0$ ) containing $0.9 \% \mathrm{NaCl}$ and $0.1 \%$ thymol prior to processing. Tooth crowns containing enamel and dentin were cut perpendicular to the longitudinal axis of each tooth using a low-speed diamond saw (IsoMet Low Speed Saw, Buehler, Lake Bluff, IL, USA) and cooled with water to reach a thickness of $1.5 \mathrm{~mm}$ respectively. The enamel parts of the dental slices were removed to get dentin slices. The dentin slice surface was mirror-polished with 600-2000 mesh sandpaper, and ultrasonically cleaned with acetone, ethanol, and deionized water alternatively (three times for 5 min each). All specimens were stored in distilled water until use to avoid dehydration.

Forty tooth slice specimens were used for the mineralization test, and 20 tooth slice specimens were used for the bleaching test. Sixty tooth slice specimens were prepared for the experiment in total. Each tooth slice was split into two parts. The first one was used for the experiment, and the other was preserved to serve as a baseline for comparison.

\section{Mineralization Protocol}

Forty tooth slice specimens were randomly selected and divided into two groups (20 specimens in each group) as following:

Experimental group: the synthesized complex paste containing calcium phosphate and HP was used for the mineralization test.

Control group: the synthesized paste without calcium phosphate was used for the mineralization test.

The dentin slices were treated with $17 \%$ ethylenediaminetetraacetic acid (EDTA) solution for $1 \mathrm{~min}$ to remove the smear layer, followed by $5.25 \% \mathrm{NaOCl}$ for $5 \mathrm{~min}$ to remove the exposed collagen matrix on the dentin surface. The dentin slices were rinsed three times with deionized water in the presence of ultrasound after EDTA and $\mathrm{NaOCl}$ treatment. Then, the 20 dentin slices samples were placed at the bottom of a sealed 24-well culture plate. The specimen surface was covered with a specific amount of the synthesized complex paste and co-cultured at $37{ }^{\circ} \mathrm{C}$ for two time points $(10$ samples for $8 \mathrm{~h}$ and 10 samples for $24 \mathrm{~h}$ ). The specimens were removed at the indicated treatment time and cleaned ultrasonically with deionized water (three times for $5 \mathrm{~min}$ each) until the surface was clear. Afterwards, the samples were dried with absorbent paper for further analysis.

\section{Characterization}

Microhardness Testing

The surface microhardness of the untreated and treated dentin slices was measured with a microhardness tester (HMV-2000; Shimadzu Corporation, Tokyo, Japan) using a Vickers diamond with a $49 \mathrm{~N}$ load applied for 15 s. Three indentations, $100 \mu \mathrm{m}$ apart, were created on the surface of each specimen. The areas selected for indentation were determined using the reflective microscope in the microhardness tester. The number of indentation points for each group was 30 (10 samples $\times 3$ indentation points) $(n=30)$.

\section{Morphology Evaluation}

Samples from each group were used for SEM observation after the microhardness test. The fractography and surface morphology features of the dentin slices were examined through SEM after the specimens were dried and sputtercoated with gold. A select area of energy disperse 
spectroscopy (EDS) was carried out to characterize the precipitation.

\section{Tooth Slice Staining and Bleaching Protocols Tooth Slice Staining}

Twenty tooth slice specimens were stained internally with a concentrated red tea solution ( $\mathrm{pH} 7.0)$ for 3 days at ambient temperature. Then, the specimens were ultrasonically cleaned with deionized water and dried with absorbent paper.

\section{Bleaching}

Twenty stained tooth slice samples from each group were placed at the bottom of a sealed 24-well culture plate. The tooth surface was covered with a specific amount of the synthesized complex paste containing calcium phosphate and $\mathrm{PH}$ for $8 \mathrm{~h}$ and $24 \mathrm{~h}$ with 10 samples each. After bleaching, the specimens were taken out, cleaned with deionized water until the paste was completely removed. The samples were kept in water and dried with absorbent paper before color testing.

\section{Color Evaluation}

The color values and differences were evaluated according to the CIE L*a*b color coordinate system $(n=10)$. Three testing areas were selected randomly for each sample. ${ }^{31,65,66} \mathrm{~L}$, a, and $b$ values represent the degree of lightness, greenness or redness, and blueness or yellowness, respectively. These values were measured with a Vita Easyshade ${ }^{\circledR}$ clinical spectrophotometer (Vident, Brea, California). follows:

The overall color difference, $\Delta \mathrm{E}$, was determined as

$$
\Delta E=\sqrt{\Delta L^{2}+\Delta a^{2}+\Delta b^{2}}
$$

where $\Delta \mathrm{L}, \Delta \mathrm{a}$, and $\Delta \mathrm{b}$ are the changes in $\mathrm{L}, \mathrm{a}$, and b values, respectively; $\Delta \mathrm{E}$ is the Euclidean distance between two points in the $3 \mathrm{D}$ space of shade and corresponds to the color difference; the coordinate $L$ represents the shade alterations at black and white scales; $a$ represents shade and saturation on the red-green axis; and $b$ represents saturation on the blue-yellow axis. ${ }^{67}$

\section{Statistical Analysis}

Means and standard deviations were calculated from the surface microhardness values and the color values measured by the CIE L*a*b color coordinate system. The equality of variances and the normal distribution of the data were tested for all variables by using Bartlett and Kolmogorov-Smirnov tests, respectively. The data showed equal variances and normal distributions, so a factor design analysis was used at the 5\% level of significance.

\section{Statement of Ethical Agreement}

All the experimental methods and protocols on the use of human tissue samples were carried out in accordance with relevant guidelines and regulations, and were approved by the Independent Ethics Committee of the Hospital of Stomatology affiliated to Hebei Medical University (document No. [2019]030).

\section{Results}

\section{Characterizing the Mineralizing Complex Paste}

The synthesized complex paste had a fine texture and gellike property and was thus easily injectable.

The XRD pattern of the mineralizing complex paste was used to evaluate the inorganic phase structure. As can be seen in the XRD spectra of all samples (Figure 1), the diffraction peaks $(002)$ at $2 \theta=26.403^{\circ},(200)$ at $2 \theta=26.594^{\circ}$, and (120) at $2 \theta=30.297^{\circ}$ corresponded to the expected peaks for monetite $\left(\mathrm{CaHPO}_{4}\right)$. Therefore, the inorganic phase of the bleaching composite was mainly $\mathrm{CaHPO}_{4}$.

The SEM micrographs of composites showed that the $\mathrm{CaHPO}_{4}$ crystals had an irregular lamellar structure with a length of 200-400 nm, width of 100-200 nm, and thickness of approximately $30 \mathrm{~nm}$ (Figure 2).

The concentration of the bleaching gel was $2.6 \% \pm 0.5 \%$ (mass/volume).

\section{SEM Analysis of Dentin Mineralization}

The dentin surface was covered by a layer of mineral crystal precipitates after $8 \mathrm{~h}$ and $24 \mathrm{~h}$ of mineralization (Figures 3 and 4). The precipitates on the dentin surface became increasingly dense (Figure 3A and B) and thick (Figure 4A and B) with prolonged mineralization time. The crystal morphology on the surface of the precipitate layer was similar to that of the mineralizing paste (Figures 2 and 3), but the crystal morphology of the precipitate layer near the dentin substrate was different from that of the mineralizing paste when viewed in the transverse sections (Figures $3 \mathrm{~B}$ and $4 \mathrm{~F}$ ). This result suggests that crystal transformation occurred during mineralization. However, the precipitated crystals on the dentin surface did not have an oriented arrangement (Figures 3 and 4).

The precipitate layer and dentin substrate tissue were interlocked (Figure 4E and F), confirming that the binding 


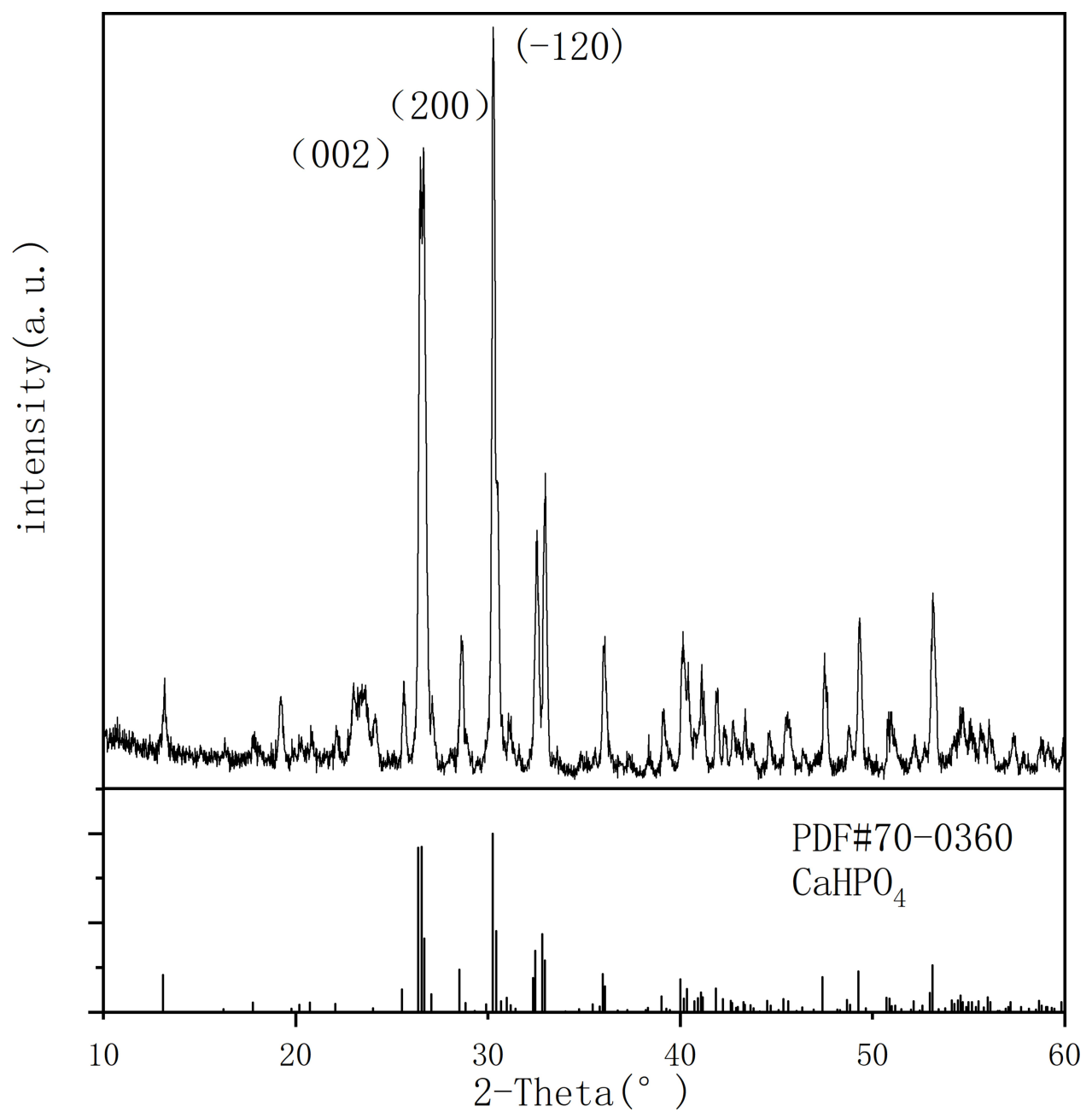

Figure I XRD pattern of the mineralizing complex and standard XRD pattern of $\mathrm{CaHPO}_{4}$ (PDF\#70-0360).
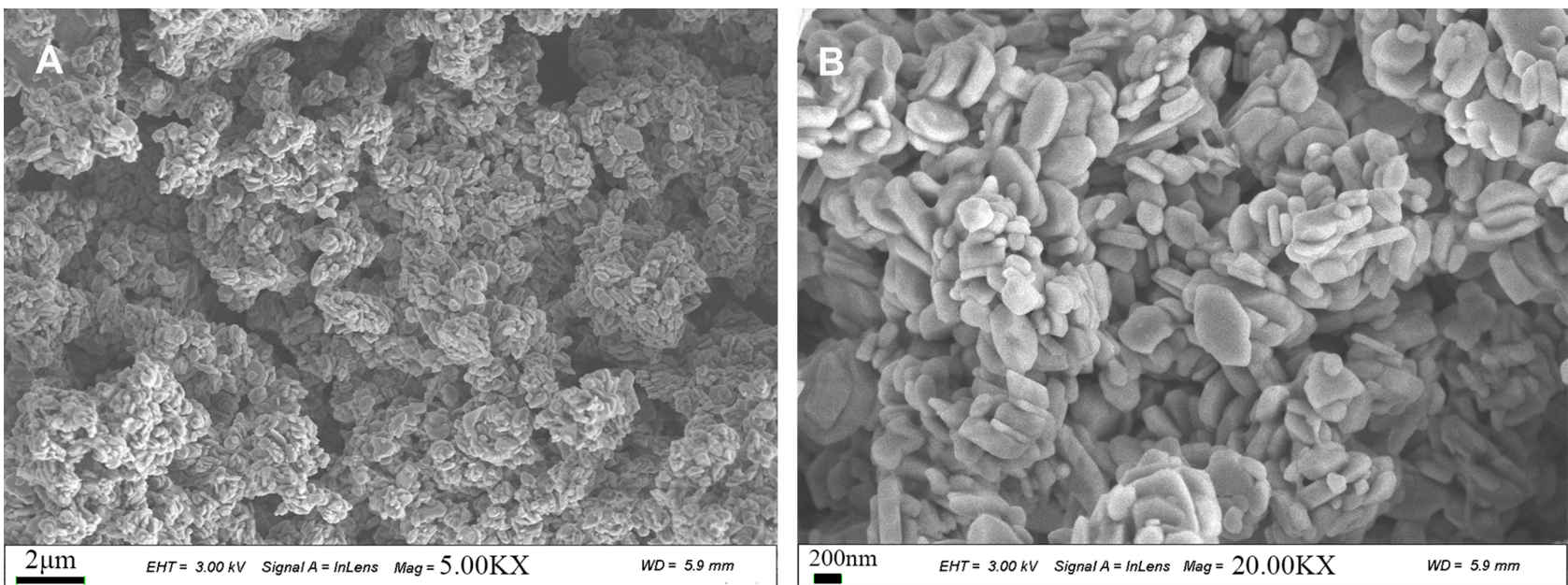

$200 \mathrm{~nm} \quad E H T=3.00 \mathrm{kV}$ Signal $\mathrm{A}=$ inLens $M a g=20.00 \mathrm{KX}$

$W D=5.9 \mathrm{~mm}$

Figure 2 SEM micrographs of the mineralizing complex paste after freeze-drying. Panel b shows a magnified image of Panel a. 


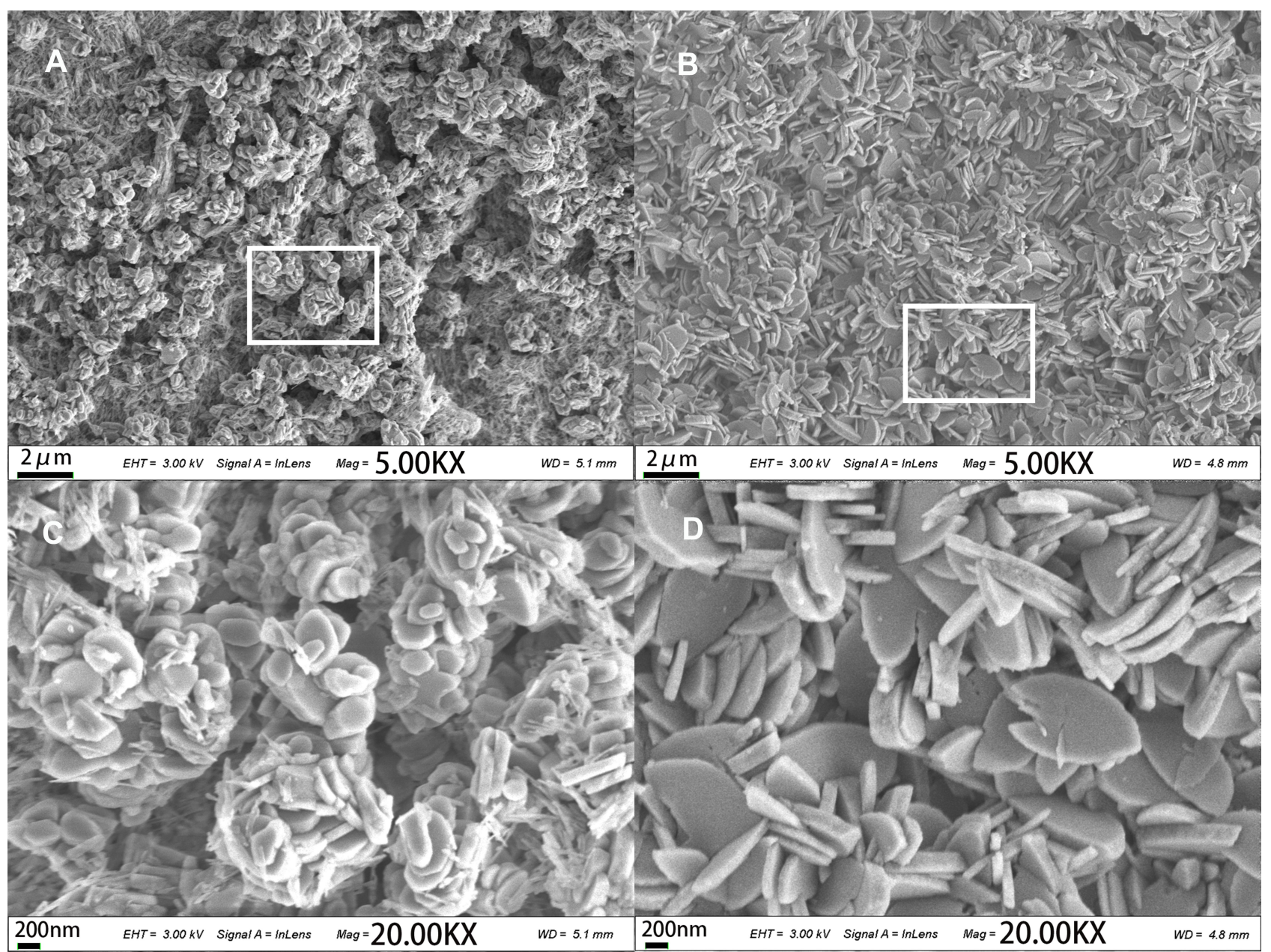

Figure 3 SEM micrographs of the dentin surface after mineralization for $8 \mathrm{~h}(\mathbf{A}$ and $\mathbf{C})$ and $24 \mathrm{~h}$ (B and D). Panels C and D show magnified views of panels A and B of “ $\square$ ” area, respectively.

between the precipitated crystals and dentin tissue was reliable.

The orifice of the dentinal tubules was completely covered by the precipitated crystals on the dentin surface (Figures 3 and 4). In the transverse sections of the mineralized dentin slices, the dentin tubule cavity was completely occluded by the densely packed crystals (Figures 4 and 5). The depth of the occluded dentin tubules reached over 80 $\mu \mathrm{m}$ (Figure 4A). A tight junction was observed at the interface between the precipitates in the dentinal tubules and the dentinal tubule wall (Figure 5). In the dentinal tubule cavity, the precipitated particles were densely packed and adhered to the wall of the dentinal tubules. In several areas, the walls and precipitates in the dentinal tubules were torn away and broken during the process of preparing the transverse sections of the samples (Figure 5B and D). The crystal morphology of the precipitates in the dentin tubules was considerably different from that of the mineralizing paste, suggesting that crystal regeneration occurred. The X-ray energy dispersive spectrum (EDS) of the regenerated crystals showed that the $\mathrm{Ca} / \mathrm{P}$ molar ratio was 1.52 (Figure 5E), indicating that the precipitated crystals may be nonstoichiometric calcium-deficient hydroxyapatite.

Figure 6 shows the morphology of dentin in the control group after treating for $8 \mathrm{~h}$ and $24 \mathrm{~h}$. The dentin collagen fibres were exposed, and the diameters of the dentinal tubules near the surface were enlarged. These findings suggest that dentin was demineralised.

\section{Microhardness of the Dentin Surface After Mineralization}

The microhardness of the precipitates on the dentin surface was evaluated using a Vickers microhardness tester. The untreated dentin samples and samples mineralized for 8 and $24 \mathrm{~h}$ had shown equal variances and normal distributions in Bartlett and Kolmogorov-Smirnov tests. The 


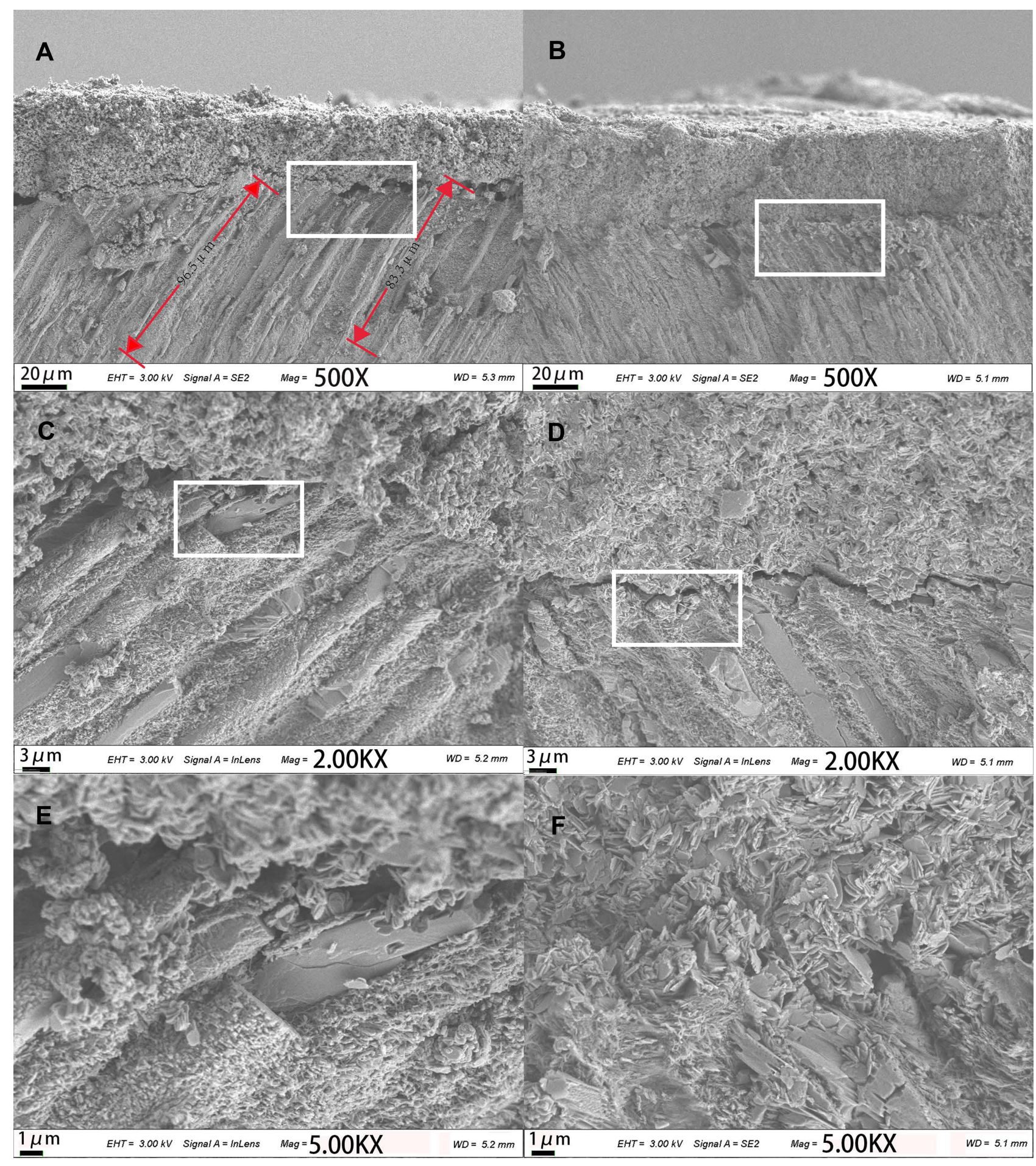

Figure 4 SEM micrographs of the transverse dentin sections after mineralization for $8 \mathrm{~h}(\mathbf{A}, \mathbf{C}$, and E) and $24 \mathrm{~h}(\mathbf{B}, \mathbf{D}$, and F). Panels C and E show magnified views of panel A of “ $\square$ " area and panel C of “ $\square$ " area at the interface of the precipitate and dentin substrate, respectively. Panels D and F show magnified views of panel B of " $\square$ " area and panel D of “ $\square$ " area at the interface of the precipitate and dentin substrate, respectively.

hardness of dentin surface in the experimental group and control group was significantly different $(\mathrm{p}<0.05$, Table 1$)$. The microhardness of both samples of experimental group and control group were lower than that of the untreated dentin $(p<0.05)$. The microhardness of the experimental group was higher than control group $(\mathrm{p}<0.05)$. When bleaching with the synthesized paste without calcium phosphate (control group), the dentin hardness was remarkably 


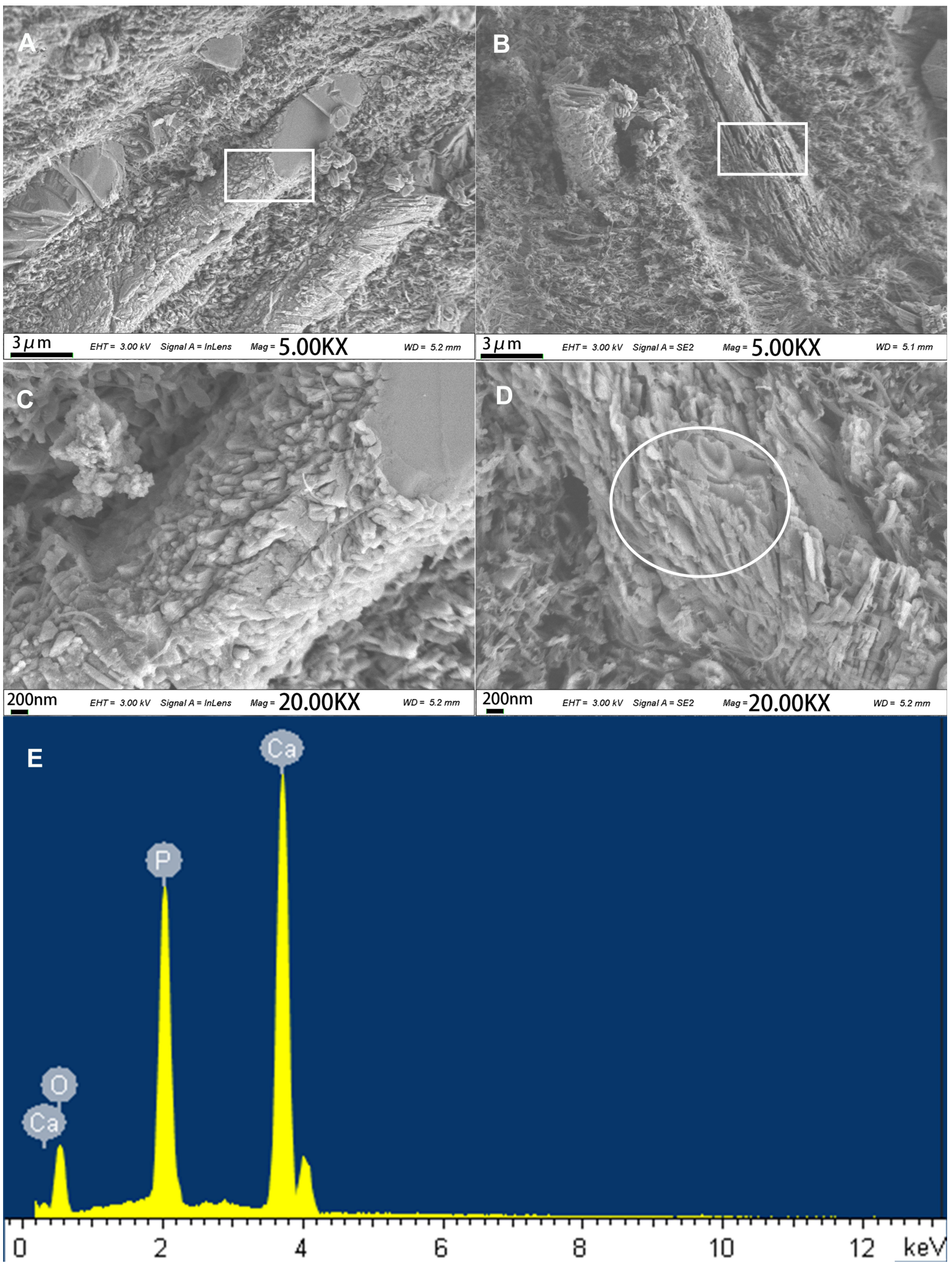

Figure 5 SEM micrographs of the transverse dentin section after mineralization for $8 \mathrm{~h}$ (A and $\mathbf{C})$ and $24 \mathrm{~h}$ (B and D). Panels $\mathrm{C}$ and $\mathrm{D}$ show magnified views of panels $A$ and B of “ $\square$ " area, respectively. The inorganic crystals grew in the dentinal tubule to occlude the dentinal tubules and integrated with dentin tissue. Panel $\mathbf{E}$ shows EDS of the regenerated crystals inside the dentin tubules selected "O" area of panel D. 


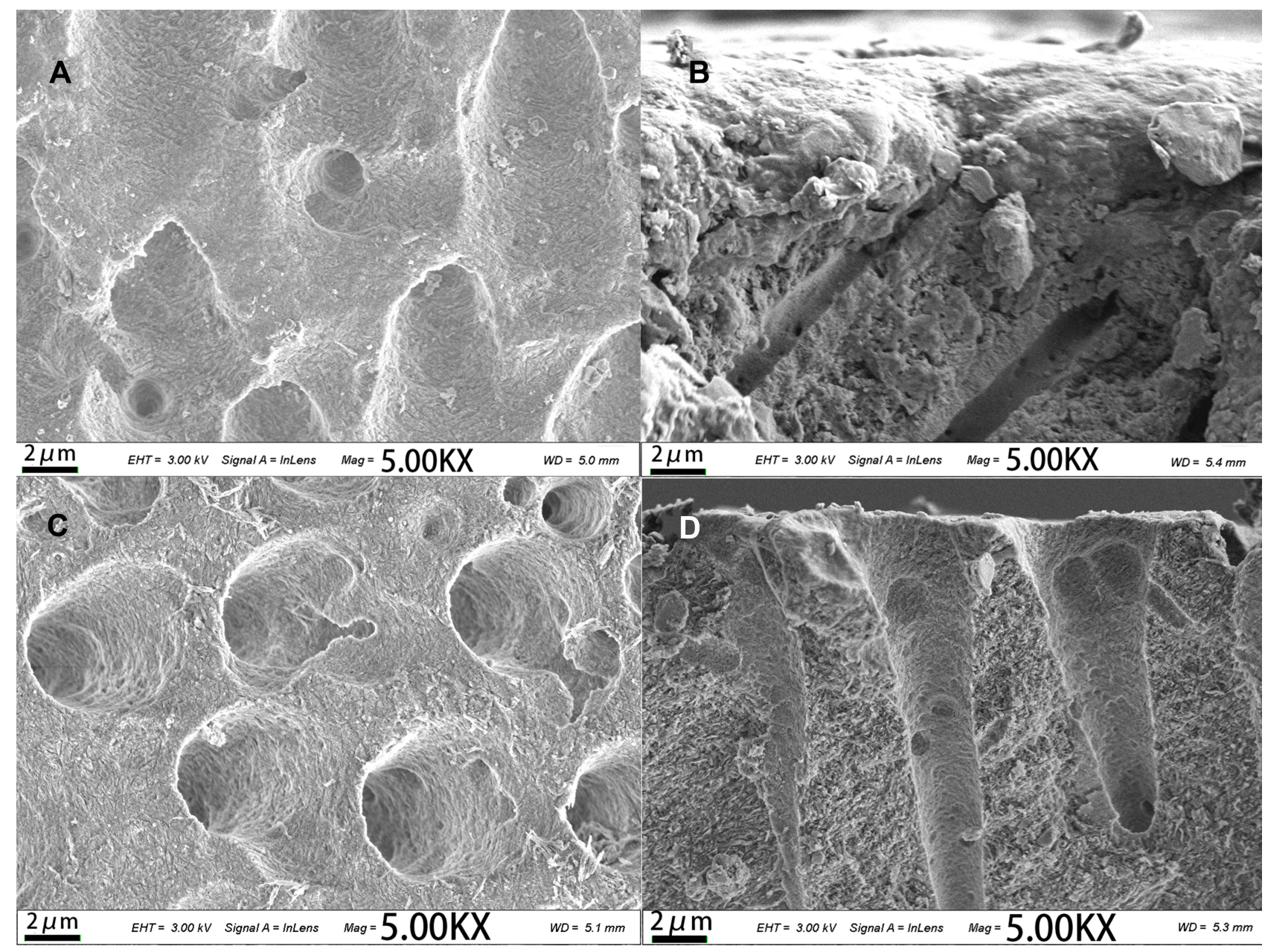

Figure 6 SEM micrographs of the dentin in the control group after treating for 8 (A and B) and $24 \mathrm{~h}(\mathbf{C}$ and $\mathbf{D})$. Panels $A$ and $C$ show the dentin surface. Panels B and $\mathrm{C}$ show the transverse section. Dentin collagen fibres were exposed, and dentinal tubules were enlarged.

declined, and the reduction was significantly increased with the treating time $(p<0.05)$. However, the hardness of dentin increased with the treating time in the experimental group $(\mathrm{p}<0.05)$.

\section{Tooth Bleaching}

The stained tooth slices were whitened after bleaching for $8 \mathrm{~h}$ and $24 \mathrm{~h}$ in vitro (Figure 7). The whitening effect in both groups for $24 \mathrm{~h}$ of bleaching was much more evident than the effect for $8 \mathrm{~h}$ of bleaching. The bleached tooth slices appeared chalky and less translucent. The digital light photographs of the tooth surface with a chalky and less translucent texture corresponded well to the SEM micrographs of mineralized samples. A layer of mineral crystals was observed precipitated on the surface of the experimental group samples (Figures 3 and 4).

The two groups' mean \pm standard deviation color value changes after tooth bleaching were evaluated using the CIE L*a*b color coordinate system (Table 1). All E values improved greatly after bleaching $(\mathrm{p}<0.05)$. The

Table I Dentin Microhardness (MPa) of Each Group

\begin{tabular}{|l|l|l|l|l|}
\hline \multirow{2}{*}{ Untreated Dentin } & \multicolumn{2}{l|}{ Experimental Group } & \multicolumn{2}{l|}{ Control Group } \\
\cline { 2 - 5 } & $\mathbf{8} \mathbf{~ h}$ & $\mathbf{2 4} \mathbf{~}$ & $\mathbf{8} \mathbf{~ h}$ & $\mathbf{2 4} \mathbf{~}$ \\
\hline$* 137.0895$ & $* 110.361905$ & $* 126.1391$ & $* 96.0222$ & $* 91.0478$ \\
\pm 9.50999 & \pm 10.17185 & \pm 8.72878 & \pm 9.46017 & \pm 10.66834 \\
\hline
\end{tabular}

Notes: Value $=$ mean \pm SD. * Significant differences were observed between any two groups after statistical analysis $(p<0.05)$. 


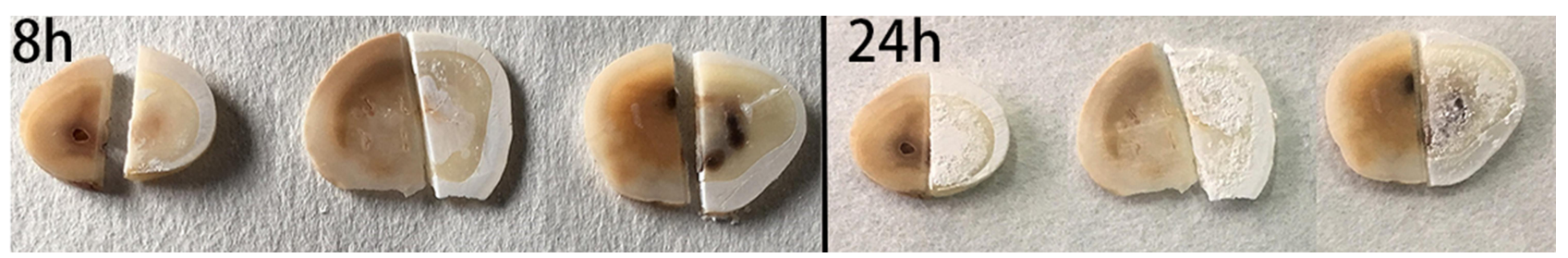

Figure 7 Bleaching effect on the tooth slices. Digital photograph of bleaching for $8 \mathrm{~h}$ and $24 \mathrm{~h}$ (with some dehydration), with the stained tooth slice before bleaching on the left and after bleaching for indicated time on the right.

$\Delta E$ color value changes exhibited a significant difference between $8 \mathrm{~h}$ and $24 \mathrm{~h}$ of bleaching $(\mathrm{p}<0.05)$.

\section{Discussion}

\section{Synthesis of the Mineralizing Complex Paste}

Three functional components were included in this mineralizing complex. Calcium phosphate acted as the mineralizing agent, high-molecular-weight PEG was used as the template controlling calcium phosphate crystal growth and maintaining paste viscosity, and HP was utilized as the bleaching agent. A mechanochemical method was adopted to synthesize the mineralizing complex, and a planetary ball mill was used to achieve a complete reaction and control the particle size.

The following stages occurred during the synthesis of the mineralizing complex. Firstly, the paste was mechanically mixed with a $\mathrm{Ca} / \mathrm{P}$ molar ratio of 1.67 under a neutral or alkaline environment to form hydroxyapatite. PEG was formulated at the hydroxyapatite to PEG weight ratio of 7:3. Secondly, the $\mathrm{pH}$ value of the paste was adjusted to 3 before addition of HP to prevent it from decomposing into water and oxygen in an alkaline environment. At this stage, hydroxyapatite transformed into monetite. Thirdly, in order to make it injectable, the paste was dried to some extent to control the HP concentration and paste viscosity. Finally, HP was added into the partly dried paste, and the HP concentration was controlled at $<3 \%$ (mass/volume), and an injectable complex paste with a fine texture and gel-like property was synthesized.

A mechanochemical method was used to synthesize the mineralizing complex in this study. It has several advantages over traditional solvent-assisted methods and has been recently used to synthesize various compounds, including apatite. ${ }^{69,70}$ In this mechanochemical synthesis, the reactants, such as $\mathrm{CaO}$ powder and $\mathrm{H}_{3}$ $\mathrm{PO}_{4}$, were co-milled. The chemical reaction was activated by the energy released from the kinetic energy of the ball vial rotation during ball collisions and the friction forces. Therefore, the desired compound was formed under a heterogeneous reacting system. This method is simple, efficient, and the size of particles is easily controlled.

\section{The Acidic Mineralizing Complex Paste Not Leading to Dentin Demineralization}

In general, a synthesized paste with a $\mathrm{pH}$ value of 3 may cause tooth demineralization, as the critical $\mathrm{pH}$ value for dentin demineralization is $6.5 .^{71}$ However, remineralization was observed in this study. The result seems to conflict with current knowledge. It was found that HP was stabilized by adding phosphoric acid in the mineralizing complex from our preliminary experiments, and the main mineral crystal was monetite $\left(\mathrm{CaHPO}_{4},\right)$ confirmed by $\mathrm{XRD}$ (Figure 1). Theoretically, the $\mathrm{Ca} / \mathrm{P}$ atomic ratio of monetite should be 1.67. However, after addition of $\mathrm{H}_{3}$ $\mathrm{PO}_{4}$, the $\mathrm{Ca} / \mathrm{P}$ atomic ratio in the paste was changed from 1.67 to approximately 1.36 . It is implied that some other amorphous calcium phosphate should have formed, as acidic conditions favored the formation of other calcium phosphates, such as calcium phosphate dihydrate and calcium-deficient hydroxyapatite. ${ }^{68}$

In addition to $\mathrm{pH}$ value, the concentrations of calcium and phosphate ions in saliva or plaque also determine the solubility of dental tissue. ${ }^{72}$ In this study, the concentration of calcium and phosphate ions was still supersaturated even under the acidic conditions. Nonetheless, it should be monetite instead of hydroxyapatite dissolving in the acidic conditions, because the solubility of monetite $\left(\mathrm{CaHPO}_{4}\right)$ in the paste is higher than that of hydroxyapatite in dentin. In 2005, Yamagishi et al. $^{73}$ reported an experimental dental 
paste that can rapidly repair early enamel caries lesions. The paste was made by adding $2 \mathrm{~mL}$ of mother solution (containing $35 \% \quad \mathrm{H}_{2} \mathrm{O}_{2}$ aqueous solution and $85 \% \mathrm{H}_{3}$ $\mathrm{PO}_{4}$ solution at a volume ratio of $4: 1$ ) to $1.5 \mathrm{~g}$ of fluorized-apatite powder to obtain a dense paste with high acidity $(\mathrm{pH}<2){ }^{73,74}$ The researchers suggested that the mechanism of rapid repair of enamel lesions is attributed to two reasons, the dissolution and regrowth of enamel apatite, and the dissociation of calcium phosphate clusters during the growth of hydroxyapatite at the interface between the paste and tooth enamel. The interface between the enamel and the paste is under-saturated due to the high acidity, which causes the dissolution of enamel at the initial stage. However, the solution around the interface is quickly supersaturated by the paste as a source of crystal enamel apatite, and hydroxyapatite regrows rapidly again; hence, continuous growth of hydroxyapatite occurs on the enamel. The process creates a continuous, nanometer-scale structure that extends from the enamel to the regrown layer via the epitaxial growth of crystals. ${ }^{72,73}$

\section{Mechanism of Mineralization Activity}

The mineralizing complex paste in the present study may have a similar mechanism of inducing mineralization as Yamagishi reported. ${ }^{72,73}$ The acidic paste may contribute to the initial dentin crystal dissolution. The calcium and phosphate ions at the interface became supersaturated and resulted in rapid crystal growth. This is confirmed by the precipitate layer interlocked with the substrate dentin tissue (Figure 4F). In our paste, the mineral phase was micro-nanosized monetite $\left(\mathrm{CaHPO}_{4}\right) . \mathrm{CaHPO}_{4}$ serves as a precursor of the tooth biomineralization and has been widely used as a hard tissue substitute due to its biocompatibility. ${ }^{30,75}$ The supersaturation for monetite $\left(\mathrm{CaHPO}_{4}\right)$ is higher than that for hydroxyapatite under highly acidic conditions. The $\mathrm{CaHPO}_{4}$ in the paste contributed to the high supersaturation of the calcium and phosphate ions or clusters around the interface between the tooth tissue and the paste and may have resulted in easy and rapid calcium phosphate transformation. ${ }^{62}$ Owing to the high supersaturation, the calcium phosphate minerals nucleated at a random orientation, which resulted in the poor mechanical properties and low crystallinity of the repaired layer away from the interface. This outcome is consistent with the results of SEM (Figures 3 and 4) and explains why the hardness of the precipitate layer on the dentin surface is lower than that of natural dentin. However, the microhardness of the precipitate layer reached 108-137 $\mathrm{MPa}$, which means the layer can withstand oral environment stresses, such as brushing force, under the no-loading occlusion surface. Meanwhile, $\mathrm{H}_{2} \mathrm{O}_{2}$ in the paste produces oxygen microbubbles that facilitate the nucleation and growth of hydroxyapatite by generating micro convection around the bubbles. ${ }^{73}$ The exact action of HP in the mineralization needs further study.

\section{In-Depth Dentin Tubule Occlusion for DH Management}

Occluding dentin tubules is the basis of DH management. The main reason for short desensitizing duration in many DH materials is the limited penetration depth of their precipitation into dentinal tubules; hence, the stresses of the oral environment cannot be tolerated. Therefore, it is necessary to develop novel materials to deeply occlude dentin tubules. New materials, including mesoporous silica nanocomposites with electrophoretic deposition, ${ }^{26,36}$ bio-calcium carbonate silica, ${ }^{43}$ and amyloid-like protein, have been tested. ${ }^{49}$ The greatest depth of occluding dentin tubules is $60 \mu \mathrm{m}$ in previous literature. In our experiment, the mineralizing depth reached $80 \mu \mathrm{m}$. The precipitate mineral was packed densely without pores in the precipitate body. The interface between the precipitate body and the wall of dentin tubules was interlocked (Figures 4 and).

The novel mineralizing complex paste in this study can also induce the growth of inorganic crystals on the dentin and enamel surface, which will integrate into the dentin tissue, and the in-depth occlusion of dentin tubules. Therefore, the developed paste can provide reliable protection for the dentin-pulp complex. The novel paste can also induce enamel remineralization (see supporting information). The enamel surface showed a fish-scale-like structure after acid etching, which indicated demineralization (Figure S1). However, when the enamel surface was covered with the paste for 8 and $24 \mathrm{~h}$, a layer of densely packed crystals precipitated on the enamel surface and bonded well to the enamel substrate (Figure S2). 
Table 2 CIE L*a*b Color Value Changes After Tooth Bleaching

\begin{tabular}{|l|l|l|l|l|}
\hline Bleaching Time & $\Delta \mathbf{L}$ & $\Delta \mathbf{a}$ & $\Delta \mathbf{b}$ & $\Delta \mathbf{E}$ \\
\hline $8 \mathrm{~h}$ & $19.38 \pm 4.56$ & $-9.00 \pm 2.68$ & $-12.61 \pm 2.15$ & $19.378 \pm 4.56$ \\
$24 \mathrm{~h}$ & $24.61 \pm 1.41$ & $10.611 \pm 0.57$ & $-17.39 \pm 0.72$ & $29.99 \pm 6.12$ \\
\hline
\end{tabular}

Notes: Significant differences were observed between the groups $(\Delta \mathrm{L}, \Delta \mathrm{a}, \Delta \mathrm{b}$ and $\Delta \mathrm{E}$ respectively) at $8 \mathrm{~h}$ and $24 \mathrm{~h}$ after statistical analysis ( $\mathrm{p}<0.05)$.

Non-carious cervical lesions are a common site for dentin hypersensitivity in dental clinics. The binding property of the mineralizing precipitate to dentin is the most important issue. Due to the the limits of our laboratory, we did not test the bond strength. In the SEM results showed that at the interface the mineralizing precipitate and dentin tissue integrated together, which implied good adhesion. The microhardness of the remineralized dentin surface was lower than that of the untreated natural dentin. This may contribute to the random precipitation of the calcium phosphate crystals on the superficial surface of the precipitating layer. However, the microhardness may still suggest the precipitate may withstand oral environment stresses under the no-loading occlusion surface.

\section{Potential Clinical Application in Simultaneous Tooth Bleaching and DH Treatment}

The mineralizing complex paste in this study has the unique potential for treating dentin hypersensitivity with simultaneous tooth bleaching. This seems conflicting as addition of HP with low $\mathrm{pH}$ may irritate the dental pulp and cause DH when a patient applies the paste. However, as mentioned above, the paste can induce dentin remineralization by occluding the dentinal tubules indepth and precipitating a layer of densely packed calcium phosphate crystals on the dentin surface, which will make the dentin less susceptible to stimuli and thus sedate DH pain. Therefore, DH caused by HP is transient. Meanwhile, the mineralizing complex paste can bleach the tooth by releasing reactive free radicals and reactive oxygen species from HP to degrade chromophores, ${ }^{64}$ as well as the calcium phosphate crystal growing on dentin surface and occluding dentinal tubules to make the tooth look lighter (Figure 7 and Table 2).

Considering its clinical application, this mineralizing complex paste is designed to be injected in a custom tray for a patient to wear at night (Figure 8 ). For this purpose, 8 $\mathrm{h}$ mineralization in the experiment was assessed to simulate the situation with the patient wearing the tray for one night, and $24 \mathrm{~h}$ for three nights. About 3\% HP was used in the paste, which consistent with 3-6\% HP concentration currently used for at-home tooth whitening. ${ }^{62,64,68}$ Further studies need to be done to optimize its clinical application.

\section{Conclusion}

In present study, a novel monetite complex paste with tooth mineralization and bleaching effects was synthesized

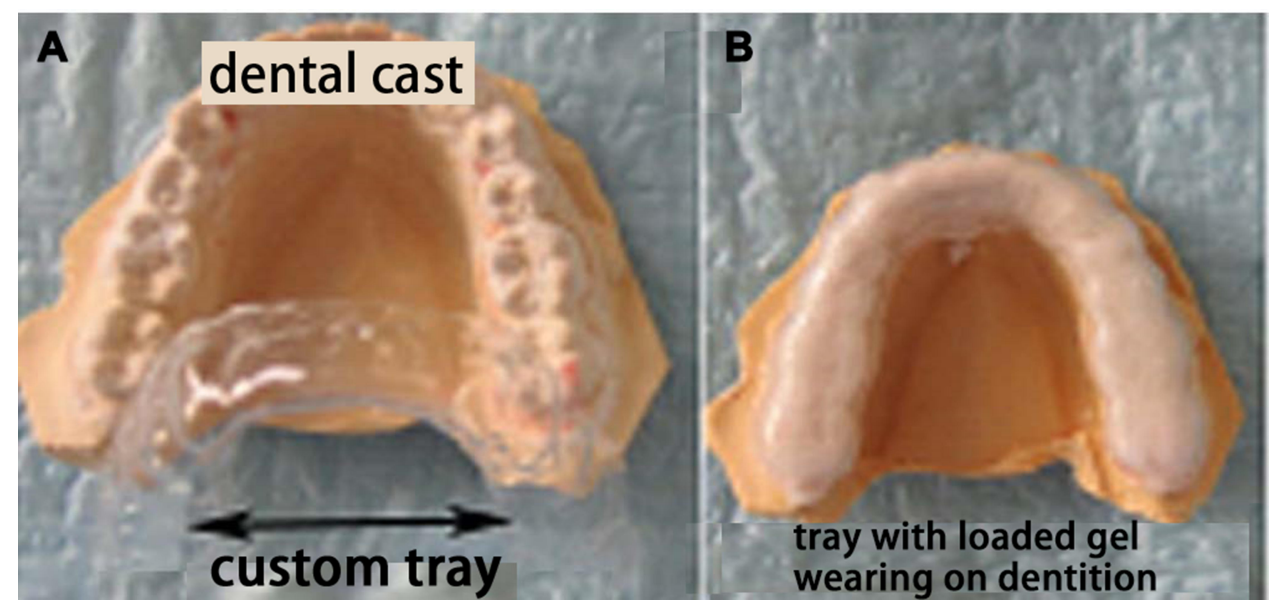

Figure 8 The potential usage for the mineralizing complex paste in clinical DH treatment. A custom tray (A) was fabricated for loading the mineralizing complex paste (B), and the patient wears it at night. 
using a mechanochemical technique. Its effects on dentin tubule occlusion and tooth bleaching were investigated in vitro. It was shown that the synthesized mineralizing complex is stable and injectable. The paste occluded dentin tubules in-depth by precipitating calcium phosphate crystals and provided a layer of densely packed calcium phosphate crystals on the dentin surface. When integrated with the substrate tooth tissue, it bleached stained dentin simultaneously. These unique properties make it a promising home-care desensitizing and bleaching product.

\section{Acknowledgment}

This work was supported by the University student Innovative Program of Hebei Medical University (No. USIP2019074). The innovation funding was from the department of science and technology, Hefei, China, (No. YW201710120001). The key programs for science and technology development of Anhui province, China (No.1804h08020232).

\section{Disclosure}

The authors report no conflicts of interest for this work.

\section{References}

1. Dowell P, Addy M. Dentine hypersensitivity - A review. Aetiology, symptoms and theories of pain production. $J$ Clin Periodontol. 1983;10(4):341-350. doi:10.1111/j.1600-051X.1983.tb01283.x

2. Miglani S, Aggarwal V, Ahuja B. Dentin hypersensitivity: recent trends in management. $J$ Conservative Dentistry. 2010;13 (4):218-224. doi:10.4103/0972-0707.73385

3. Shiau HJ. Dentin Hypersensitivity. J Evi Based Dental Practice. 2012;12(3):220-228. doi:10.1016/S1532-3382(12)70043-X

4. Splieth $\mathrm{CH}$, Tachou A. Epidemiology of dentin hypersensitivity. Clin Oral Investig. 2013;17(S1):3-8. doi:10.1007/s00784-012-0889-8

5. Wang Y, Que K, Lin L, Hu D, Li X. The prevalence of dentine hypersensitivity in the general population in China. J Oral Rehabil. 2012;39(11):812-820. doi:10.1111/j.1365-2842.2012.02334.x

6. Rees JS, Addy M. A cross-sectional study of dentine hypersensitivity. $J$ Clin Periodontol. 2002;29(11):997-1003. doi:10.1034/j.1600051X.2002.291104.x

7. Brännström M. Dentin sensitivity and aspiration of odontoblasts. J Am Dent Assoc. 1963;66(3):366-370.

8. Pashley DH. Dentine permeability and its role in the pathobiology of dentine sensitivity. Arch Oral Biol. 1994;39:73S-80S.

9. Gillam DG, Orchardson R. Advances in the treatment of root dentine sensitivity: mechanisms and treatment principles. Endod Topic. 2006;13(1):13-33.

10. Tan S, Chen S, Wang Y, et al. Enhanced effect of nano-monetite hydrosol on dentin remineralization and tubule occlusion. Dent Mater. 2020;36(6):816-825. doi:10.1016/j.dental.2020.03.028

11. Figueiredo Macedo de Lima J, Aguiar Jordão Mainardi MDC, PuppinRontani RM, et al. Bioinspired catechol chemistry for dentin remineralization: A new approach for the treatment of dentin hypersensitivity. Dent Mater. 2020;36(4):501-511. doi:10.1016/j.dental.2020.01.012
12. Clark D, Levin L. Non-surgical management of tooth hypersensitivity. Int Dental J. 2016;66(5):249-256. doi:10.1111/idj.12247

13. Hines $\mathrm{D}, \mathrm{Xu} \mathrm{S}$, Stranick M, et al. Effect of a stannous fluoride toothpaste on dentinal hypersensitivity: in vitro and clinical evaluation. $J$ Am Dent Assoc. 2019;150(4):S47-S59. doi:10.1016/j. adaj.2019.01.006

14. Creeth J, Gallob J, Sufi F, et al. Randomised clinical studies investigating immediate and short-term efficacy of an occluding toothpaste in providing dentine hypersensitivity relief. BMC Oral Health. 2019;19(1):98-99. doi:10.1186/s12903-019-0781-x

15. Saeki K, Marshall GW, Gansky SA, Parkinson CR, Marshall SJ. Strontium effects on root dentin tubule occlusion and nanomechanical properties. Dent Mater. 2016;32(2):240-251. doi:10.1016/j. dental.2015.11.020

16. Sameera U, Bilichodmath S, Paul P. Evaluation of the Efficacy of Strontium Chloride, Biodentine(R) and Biodentine(R) in Combination with Diode Laser in the Management of Dentinal Hypersensitivity- An In vitro SEM Study. $J$ Int Acad Periodontol. 2019;21(2):74-81.

17. Varoni EM, Zuccheri T, Carletta A, et al. In vitro efficacy of a novel potassium oxalate hydrogel for dentin hypersensitivity. Eur J Oral Sci. 2017;125(2):151-159. doi:10.1111/eos.12334

18. Lynch MC, Perfekt R, McGuire JA, et al. Potassium oxalate mouthrinse reduces dentinal hypersensitivity: A randomized controlled clinical study. J Am Dent Assoc. 2018;149(7):608-618. doi:10.1016/j. adaj.2018.02.027

19. Cunha-Cruz J, Stout JR, Heaton LJ, Wataha JC. Dentin Hypersensitivity and Oxalates. J Dent Res. 2011;90(3):304-310. doi:10.1177/0022034510389179

20. Sereda G, Saeedi S. Pre-treatment of dentin with chondroitin sulfate or L-arginine modulates dentin tubule occlusion by toothpaste components. Am J Dent. 2019;32(2):81-88.

21. Karim BFA, Gillam DG. The Efficacy of Strontium and Potassium Toothpastes in Treating Dentine Hypersensitivity: A Systematic Review. Int $J$ Dentistry. 2013;2013:573258. doi:10.1155/2013/ 573258

22. Bakry AS, Al-Hadeethi Y, Razvi MAN. The durability of a hydroxyapatite paste used in decreasing the permeability of hypersensitive dentin. J Dent. 2016;51:1-7. doi:10.1016/j.jdent.2016.05.004

23. Enax J, Epple M. Synthetic Hydroxyapatite as a Biomimetic Oral Care Agent. Oral Health Prev Dent. 2018;16(1):7-19.

24. Taha ST, Han H, Chang S-R, et al. Nano/micro fluorhydroxyapatite crystal pastes in the treatment of dentin hypersensitivity: an in vitro study. Clin Oral Investig. 2015;19(8):1921-1930. doi:10.1007/s00784-015-1427-2

25. Yu Q, Liu H, Liu Z, et al. Comparison of nanofluoridated hydroxyapatite of varying fluoride content for dentin tubule occlusion. $\mathrm{Am}$ $J$ Dent. 2017;30(2):109-115.

26. Baglar S, Erdem U, Dogan M, Turkoz M. Dentinal tubule occluding capability of nano-hydroxyapatite; The in-vitro evaluation. Microsc Res Tech. 2018;81(8):843-854. doi:10.1002/jemt.23046

27. Iafisco M, Degli Esposti L, Ramírez-Rodríguez GB, et al. Fluoridedoped amorphous calcium phosphate nanoparticles as a promising biomimetic material for dental remineralization. Sci Rep. 2018;8 (1):17016. doi:10.1038/s41598-018-35258-x

28. Seong J, Davies M, Macdonald EL, Claydon NC, West NX. Randomized clinical trial to determine if changes in dentin tubule occlusion visualized by SEM of replica impressions correlate with pain scores. Am J Dent. 2018;31(4):189-194.

29. Favretto CO, Delbem ACB, Moraes JCS, Camargo ER, de Toledo PTA, Pedrini D. Dentinal tubule obliteration using toothpastes containing sodium trimetaphosphate microparticles or nanoparticles. Clin Oral Investig. 2018;22(9):3021-3029. doi:10.1007/s00784-018-2384-3

30. Sauro S, Lin C-Y, Bikker FJ, et al. Di-Calcium Phosphate and Phytosphingosine as an Innovative Acid-Resistant Treatment to Occlude Dentine Tubules. Caries Res. 2016;50(3):303-309. doi: $10.1159 / 000445444$ 
31. Osorio R, Toledano-Osorio M, Osorio E, Aguilera FS, PadillaMondéjar S, Toledano M. Zinc and silica are active components to efficiently treat in vitro simulated eroded dentin. Clin Oral Investig. 2018;22(8):2859-2870. doi:10.1007/s00784-018-2372-7

32. Greenspan DC. NovaMin and tooth sensitivity-an overview. J Clin Dent. 2010;21(3):61-65.

33. Bakri MM, Hossain MZ, Razak FA, et al. Dentinal tubules occluded by bioactive glass-containing toothpaste exhibit high resistance toward acidic soft drink challenge. Australian Dental J. 2017;62 (2):186-191. doi:10.1111/adj.12484

34. Ma Q, Wang T, Meng Q, et al. Comparison of in vitro dentinal tubule occluding efficacy of two different methods using a nano-scaled bioactive glass-containing desensitising agent. $J$ Dent. 2017;60:63-69. doi:10.1016/j.jdent.2017.03.001

35. Dong Z, Yang Q, Mei M. Preparation and characterization of fluoride calcium silicate composites with multi-biofunction for clinical application in dentistry. Composites Part B. 2018;143:243-249. doi:10.1016/j.compositesb.2018.02.009

36. Muruppel AM, George AA, Lal S. A Comparative Evaluation of the Effectiveness of Three Different Modalities in Occluding Dentinal Tubules: an In Vitro Study. J Contemp Dent Pract. 2019;20 (4):454-459. doi:10.5005/jp-journals-10024-2538

37. Yu T, Wang Y, Cai Q, Wu L. Efficacy of Ca2+- or PO43--conjugated mesoporous silica nanoparticles on dentinal tubule occlusion: an in-vitro assessment. Ann Transl Med. 2020;8(5):173. doi:10.21037/ atm.2020.01.98

38. Zhang L, Sun H, Yu J, Yang H, Song F, Huang C. Application of electrophoretic deposition to occlude dentinal tubules in vitro. J Dent. 2018;71:43-48. doi:10.1016/j.jdent.2018.01.012

39. Jung J-H, Park S-B, Yoo K-H, et al. Effect of different sizes of bioactive glass-coated mesoporous silica nanoparticles on dentinal tubule occlusion and mineralization. Clin Oral Investig. 2019;23 (5):2129-2141. doi:10.1007/s00784-018-2658-9

40. Yu J, Yang H, Li K, Lei J, Zhou L, Huang C. A novel application of nanohydroxyapatite/mesoporous silica biocomposite on treating dentin hypersensitivity: an in vitro study. J Dent. 2016;50:21-29. doi:10.1016/j.jdent.2016.04.005

41. Sufi F, Hall C, Mason S, Shaw D, Kennedy L, Gallob JT. Efficacy of an experimental toothpaste containing $5 \%$ calcium sodium phosphosilicate in the relief of dentin hypersensitivity: an 8-week randomized study (Study 1). Am J Dent. 2016;29(2):93-100.

42. Wang Y-L, Chiang Y-C, Chang -H-H, Lin H-P, Lin C-P. Novel calcium encapsulated mesocellular siliceous foams for crystal growth in dentinal tubules. J Dent. 2019;83:61-66. doi:10.1016/j.jdent.2019.02.007

43. Chang HH, Yeh CL, Wang YL, Liu GW, Lin HP, Lin CP. Crystal growth in dentinal tubules with bio-calcium carbonate-silica sourced from equisetum grass. J Formos Med Assoc. 2020.

44. Öncü E, Karabekiroğlu S, Ünlü N. Effects of different desensitizers and lasers on dentine tubules: an in-vitro analysis. Microsc Res Tech. 2017;80(7):737-744. doi:10.1002/jemt.22859

45. Oh S, Gu Y, Perinpanayagam H, et al. Dentinal tubule sealing effects of 532-nm diode-pumped solid-state laser, gallic acid/Fe3+ complex, and three commercial dentin desensitizers. Lasers Med Sci. 2018;33 (6):1237-1244. doi:10.1007/s10103-018-2464-2

46. Marto CM, Baptista Paula A, Nunes T, et al. Evaluation of the efficacy of dentin hypersensitivity treatments - A systematic review and follow-up analysis. J Oral Rehabil. 2019;46(10):952-990. doi:10.1111/joor.12842

47. Oh DX, Prajatelistia E, Ju S-W, et al. A rapid, efficient and facile solution for dental hypersensitivity: the tannin-iron complex. Sci Rep. 2015;5(1):10884. doi:10.1038/srep10884

48. Prajatelistia E, Ju S-W, Sanandiya ND, Jun SH, Ahn J-S, Hwang DS. Tunicate-Inspired Gallic Acid/Metal Ion Complex for Instant and Efficient Treatment of Dentin Hypersensitivity. Adv Healthc Mater. 2016;5(8):919-927. doi:10.1002/adhm.201500878
49. Song J, Wang H, Yang Y, et al. Nanogels of carboxymethyl chitosan and lysozyme encapsulated amorphous calcium phosphate to occlude dentinal tubules. J Mater Sci Mater Med. 2018;29(6):84. doi:10.1007/ s10856-018-6094-9

50. Li C, Lu D, Deng J, Zhang X, Yang YP. Amyloid-Like Rapid Surface Modification for Antifouling and In-Depth Remineralization of Dentine Tubules to Treat Dental Hypersensitivity. Adv Mater. 2019;31(46):e1903973. doi:10.1002/adma.201903973

51. Schlee M, Rathe F, Bommer C, Bröseler F, Kind L. Self-assembling peptide matrix for treatment of dentin hypersensitivity: A randomized controlled clinical trial. $J$ Periodontol. 2018;89(6):653-660. doi:10.1002/JPER.17-0429

52. West NX, Seong J, Hellin N, Macdonald EL, Jones SB, Creeth JE. Assessment of tubule occlusion properties of an experimental stannous fluoride toothpaste: A randomised clinical in situ study. J Dent. 2018;76:125-131. doi:10.1016/j.jdent.2018.07.001

53. Guentsch A, Seidler K, Nietzsche S, et al. Biomimetic mineralization: long-term observations in patients with dentin sensitivity. Dent Mater. 2012;28(4):457-464. doi:10.1016/j.dental.2012.01.003

54. Zhu M, Li J, Chen B, et al. The Effect of Calcium Sodium Phosphosilicate on Dentin Hypersensitivity: A Systematic Review and Meta-Analysis. PLoS One. 2015;10(11):e0140176. doi:10.1371/ journal.pone. 0140176

55. Douglas-de-Oliveira DW, Vitor GP, Silveira JO, Martins CC, Costa FO, Cota LOM. Effect of dentin hypersensitivity treatment on oral health related quality of life - A systematic review and meta-analysis. J Dent. 2018;71:1-8. doi:10.1016/j.jdent.2017.12.007

56. de Melo Alencar C, de Paula BLF, Guanipa Ortiz MI, Baraúna Magno M, Martins Silva C, Cople Maia L. Clinical efficacy of nano-hydroxyapatite in dentin hypersensitivity: A systematic review and meta-analysis. J Dent. 2019;82:11-21. doi:10.1016/j.jdent.2018.12.014

57. Arantes DC, Limeira FIR, Yamauti M, Moreira AN, Abreu LG, Magalhães CS. Comparison of clinical efficacy of pro-argin and NovaMin toothpastes in relieving dentin hypersensitivity: A systematic review and meta-analysis. Oral Health Prev Dent. 2019;17(5):403-412.

58. Cunha-Cruz J, Zeola LF. Limited Evidence Suggests That Many Types of Desensitizing Toothpaste May Reduce Dentin Hypersensitivity, but Not the Ones With Strontium or Amorphous Calcium Phosphate. Journal of Evidence Based Dental Practice. 2019;19(4):101337. doi:10.1016/j.jebdp.2019.101337

59. Hu M-L, Zheng G, Zhang Y-D, Yan X, Li X-C, Lin H. Effect of desensitizing toothpastes on dentine hypersensitivity: A systematic review and meta-analysis. J Dent. 2018;75:12-21. doi:10.1016/j. jdent.2018.05.012

60. Konradsson K, Lingström P, Emilson CG, Johannsen G, Ramberg P, Johannsen A. Stabilized stannous fluoride dentifrice in relation to dental caries, dental erosion and dentin hypersensitivity: A systematic review. Am J Dent. 2020;33(2):95-105.

61. Khijmatgar S, Reddy U, John S, Badavannavar AN, Ds T. Is there evidence for Novamin application in remineralization?: A systematic review. Journal of Oral Biology and Craniofacial Research. 2020;10 (2):87-92. doi:10.1016/j.jobcr.2020.01.001

62. Carey CM. Tooth whitening: what we now know. Journal of Evidence Based Dental Practice. 2014;14:Suppl:70-76. doi:10.1016/j.jebdp.2014.02.006

63. Beall AE. Can a new smile make you look more intelligent and successful? Dent Clin North Am. 2007;51(2):289-297. doi:10.1016/ j.cden.2007.02.002

64. Joiner A. Review of the effects of peroxide on enamel and dentine properties. $J \quad$ Dent. 2007;35(12):889-896. doi:10.1016/j. jdent.2007.09.008

65. Borges BC, Borges JS, de Melo CD, et al. Efficacy of a novel at-home bleaching technique with carbamide peroxides modified by CPP-ACP and its effect on the microhardness of bleached enamel. Oper Dent. 2011;36(5):521-528. doi:10.2341/11-013-L 
66. Silva CM, de Lima Gomes YS, Alexandrino LD, de M Alencar C, Alves EB. In situ effect of nanohydroxyapatite paste in enamel teeth bleaching. $J$ Contemp Dent Pract. 2017;18(11):996-1003. doi:10.5005/jp-journals-10024-2164

67. Alexandrino LD, Alencar CDM, Silveira A, Alves EB, Silva CM. Randomized clinical trial of the effect of NovaMin and CPP-ACPF in combination with dental bleaching. J Appl Oral Sci. 2017;25 (3):335-340. doi:10.1590/1678-7757-2016-0408

68. Alkhtib A, Manton DJ, Burrow MF, et al. Effects of bleaching agents and Tooth Mousse TM on human enamel hardness. $J$ Investig Clin Dent. 2013;4(2):94-100. doi:10.1111/jicd.12001

69. Chaikina M, Bulina N, Vinokurova O, Prosanov I, Dudina D. Interaction of calcium phosphates with calcium oxide or calcium hydroxide during the "soft" mechanochemical synthesis of hydroxyapatite. Ceram Int. 2019;45.

70. Mondal S, Hoang G, Manivasagan P, et al. Rapid microwave-assisted synthesis of gold loaded hydroxyapatite collagen nano-bio materials for drug delivery and tissue engineering application. Ceram Int. 2019;45(3):2977-2988.
71. Ferreira Zandoná AG, Ritter AV, Eidson RS. 2 - Dental Caries: etiology, Clinical Characteristics, Risk Assessment, and Management. In: Ritter AV, Boushell LW, Walter R, editors. Sturdevant's Art and Science of Operative Dentistry. Elsevier; 2019:40-94.

72. Borges AB, Guimaräes CA, Bresciani E, Ramos CJ, Borges AL. Rocha Gomes Torres C. Effect of incorporation of remineralizing agents into bleaching gels on the microhardness of bovine enamel in situ. J Contemp Dent Pract. 2014;15(2):195-201.

73. Yamagishi K, Onuma K, Suzuki T, et al. Materials chemistry: a synthetic enamel for rapid tooth repair. Nature. 2005;433 (7028):819.

74. Onuma K, Yamagishi K, Oyane A. Nucleation and growth of hydroxyapatite nanocrystals for nondestructive repair of early caries lesions. J Cryst Growth. 2005;282(1):199-207.

75. Elsharkawy S, Mata A. Hierarchical biomineralization: from nature's designs to synthetic materials for regenerative medicine and dentistry. Adv Healthc Mater. 2018;7(18):e1800178.
International Journal of Nanomedicine

\section{Publish your work in this journal}

The International Journal of Nanomedicine is an international, peerreviewed journal focusing on the application of nanotechnology in diagnostics, therapeutics, and drug delivery systems throughout the biomedical field. This journal is indexed on PubMed Central, MedLine, CAS, SciSearch ${ }^{\mathbb{R}}$, Current Contents ${ }^{\mathbb{B}} /$ Clinical Medicine, $^{2}$
Journal Citation Reports/Science Edition, EMBase, Scopus and the Elsevier Bibliographic databases. The manuscript management system is completely online and includes a very quick and fair peer-review system, which is all easy to use. Visit http://www.dovepress.com/ testimonials.php to read real quotes from published authors. 